\title{
Introduction to the Issue on Equity, Collaboration, and Empowerment in Mental Health Research Partnerships
}

\author{
Manasi Kumar ${ }^{1}$ - Ozge Sensoy Bahar ${ }^{2}$ \\ Published online: 5 August 2019 \\ (C) Springer Nature Switzerland AG 2019
}

\section{Context}

We take this opportunity to introduce the special issue on "Equity, Collaboration, and Empowerment in Mental Health Research Partnerships." The specific focus of this issue has been galvanized by a multi-country collaborative NIMH-funded research center (U19MH110001; 20162021) led by Global Social Welfare Editors Drs. Mary McKay and Fred Ssewamala along with other mental health researchers from Ghana, Kenya, South Africa, Uganda, and the United States (U.S.). Entitled "Strengthening Mental health And Research Training in Sub-Saharan Africa" Center (SMART Africa Center), this center cuts across geographical boundaries, disciplines, and expertise, and aspires to build truly collaborative partnerships. The role of this special issue was to contribute to the knowledge base on practices that either impede or strengthen partnership research stances that enrich crosscultural research.

In a world of increasing interest in global research, the field of mental health is brimming with new research ideas and requiring more research collaborations across countries. Partnerships imply collaborative work between researchers from different disciplines, factions, sociodemographic groups, and cultures. These also offer opportunity for greater engagement between varied geopolitical regions. Yet, these endeavors have also exposed several uncharted needs.

Manasi Kumar

m.kumar@ucl.ac.uk

Department of Psychiatry, University of Nairobi, Nairobi, Kenya

2 Brown School, Washington University in St. Louis, St. Louis, MO, USA

\section{Equity, Collaboration, Empowerment: a Human Rights Approach}

Equity implies giving equal opportunities in both space and time for diverse set of people with differential capabilities to succeed. Global health research has taken a huge surge in the Global South particularly in Africa (Chu et al. 2014). The wide-ranging social determinants associated with morbidity and mortality and multi-level implementation problems have opened doors to studying new concerns and populations, using new study designs and approaches in order to address health disparities, including mental health, in the Global South.

In trying to address local problems in joint research enterprise, global partnerships may have good will and a model of furthering scientific enterprise at the core. Despite this common goal, the issue of how benefits, resources, and knowledge are developed and shared continues to be problematic (Aellah et al. 2016; Lairumbi et al. 2011). We argue that in unequal partnerships, the division of labor can be such that the Global South scholars are trained to become experts in field work, to abide by procedural ethics of the data collection and embrace participatory work with human subjects via Western lenses, and once the data is collected, it is developed into more sophisticated science by the Northern researchers. In this process, two trends can be seen. Lately, there is a growing trend to include a number of Southern researchers in the publications and research processes but the entire scheme is orchestrated by key international partners, including funding partners, donors, or researchers from the North, without a true dialogue around cross-cultural synergies (Gautier et al. 2018). The other trend is to eulogize the local partners in local meetings without actually acknowledging or embracing them in more global and advanced forums, including in formal publications. Both attitudes perpetuate injustice and inequity given the Southern hemisphere's historical landscape where colonization and collective oppression have left indelible marks (Kumar 2019). 
The partnerships and collaborations are highly strategic, yet often silent in questioning oppressive practices and problematic unethical or inequities between North and South as well as within Southern contexts, intercultural relations, or those fossilized within academics.

A useful distinction has been made between "procedural ethics" and "ethics in practice" in this regard (Simon and Mosavel 2011). The visible absence of ethics-in-practice in global research collaborations in Africa needs to be addressed vigorously (Myser 2015). The researchers from Global North can often be utilitarian in their approach trying to further their own careers with less focus on sustainable capacity building, empowering local populations (Gautier et al. 2018), and issuebased research where research is guided by questions generated by the real social context in which the project is undertaken (Bosio and Graffigna 2012), hence acknowledging the needs and priorities of the locality. The peer-to-peer and institution-to-institution relationships can easily become skewed, driven entirely by research output for Global North researchers and short-term financial incentives and development of static power hubs for Global South researchers. None of these stances make a lasting mark on the science or impact the research participants in any significant, let alone sustainable manner.

Various strategies can be adopted to decentralize these long-lasting practices. The partnerships should prioritize and invest in a bi-directional exchange and learning model that steps away from privileging and solely valuing Western paradigms, knowledge, and practices, and engage in true collaboration with partners from the South that respects, adopts, and learns from the knowledge, expertise, and values of the local partners (Parker et al. 2014). Collaborative processes can become the foundation for new solutions to serious global problems (McKay and Paikoff 2007; Sperber et al. 2008) and should be based on the following five core principles: (1) agreement and investment in shared goals; (2) equitable distribution of power, including fair involvement in decisionmaking and opportunities to change aspects of the action plan; (3) recognition of skills and expertise, but equally incorporating local knowledge and perspectives; (4) ongoing communication based upon commitment to honest exchanges and willingness to raise concerns without blame; and (5) trust (McKay and Jensen 2010; Parker et al. 2014).

The research agendas have to be led by the Global South team and allow a significant leadership to develop. This would require investing resources in capacity building, leadership, and local development in science by Southern countries. For example, it is through focusing on African institutions investing in African researchers in their respective institutions and keeping them in the forefront that equity can be achieved.

Moreover, there is a strong need to develop global ethicsin-practice dialogues where practices are deliberated and concepts and definitions articulated collaboratively and from different vantage points. Understanding of ethics and practicing ethical global research might vary from one region to the other. A dialogical approach ensures that equal participation and opportunities as scientists, scholars, and leaders are seen as an ethical and human right priority in global mental health and mutually agreed upon ethical standards are applied. Heralding human rights approach as central to the process of collaboration and partnerships, this issue highlights how researchers from across the world experienced and addressed issues they have encountered in North-South research collaborations.

\section{Contributions from Our Special Issue Authors}

Breuer and colleagues from the DFID-funded PRIME study "Partnerships in a global mental health research programme the example of PRIME" provide a comprehensive framework utilizing Tuckman's stages of partnerships. This multi-country program led by Global South researchers devoted itself to developing partnerships and theory of change models that guided mental health system development in India, Ethiopia, Nepal, Uganda, and South Africa. In describing the critical stages of the research partnership development, Breuer and colleagues note that "the initial stages of the consortium required time to build trust and create a safe space to express different views, thus facilitating implementation country partners to have an influential voice in the decision making within the partnership. In that way, it was possible to balance the contextual environments with the quality and appropriateness of the research" (p. 23). Trust, secure bonding, and the opportunity for different partners to relay concerns without any compunction were key elements of PRIME's success as shared by Breuer and colleagues.

In a paper entitled "Building cardiovascular disease (CVD) competence in an urban poor Ghanaian community: a social psychology of participation approach," De Graft Aikins and colleagues present a case study from Accra around cardiovascular disease detection and management capacity building and offer some insights on what a collaborative community-based participatory process is like. Embedded within Bourdieu and Campbell's theories of how competent research and practice communities' function, Ama and her colleagues share a novel model for implementing a longitudinal study driven by community stakeholders in determining the social psychological strategies to address CVDs in a Ghanaian settlement of Ga Machie.

The special issue featured two very interesting commentaries. Each of these papers gave premium to generation of multisectoral dialogue and using dialogue to promote open communication, thereby increasing receptivity to ideas to promote change mental health practice and systems. 
The first commentary was from Larry Palinkas on "Equity and Exchange in Global Research-Practice Partnerships." In trying to clarify the true purpose of community-based participatory research (CBPR) and community-partnered participatory research (CPPR), Palinkas astutely remarks that "the extent of collaboration between researchers and practitioners is often dependent upon the willingness and ability to exchange information and values through their interactions. This cultural exchange is a transaction of knowledge, attitudes and practices that occurs when two individuals or groups of individuals representing diverse cultural systems" (p. 3). In this paper, communication and openness to change are critical to the three stages Palinkas alludes to.

Adsul and Chambers in their commentary paper on "Advancing research practice partnerships to achieve population level mental health outcomes" promote the idea of participatory processes to extend dissemination and implementation thinking in mental health.

We received papers that exclusively devoted themselves to discussing mental health capacity building using crosscountry partnerships. These papers reflected on the existing praxes and opportunities for enhancing mental health research capacity and systems through partnerships with US institutions. Case studies from different countries across Africa, Latin America, and Asia discussed partnership challenges and successes.

Mathai and colleagues presented a systematic appraisal of how focused partnerships using Southern partners as joint investigators allow for more room to make meaningful adjustments and decision-making for enhanced capacity building using Kenya as an example. In their paper "Building Mental Health Research Capacity in Kenya: A South - North Collaboration," an argument is made that the capacity building needs to be driven by the South partners so that real needs and priorities can be addressed.

Informed by intersectionality framework, our contributors, Tabb and Valdovinos, use collaborative auto-ethnography as a way of critically reflecting on "Social Workers Conducting Maternal Health Services Research in the Global South." More specifically, they examine three dimensions of their intersectional (race, gender, and class) social identities in a Peruvian cultural and research context, and illustrate how power and privilege, cultural humility, and awareness of colonization play out in collaborations between Global North and Global South maternal health services research partnerships.

Baumann and colleagues reflect on the collaboration process of a team of parenting program researchers with their partners globally in generating local knowledge by balancing the need for rigorous scientific methods with issues of power. The authors from the USA, Latin America, Africa, and Southeast Asia draw on their experiences regarding challenges and successes with issues regarding study design, cultural adaptation, and implementation while placing communities at the center of their efforts through participatory methods. Using examples from their own work, the authors point out the importance of bidirectionality both within a Global South country (e.g., among researchers, communities, policymakers) and between Global North and South.

Guided by the Tropical Health and Education Trust (THET) Framework, Witte and her colleagues use two collaborative research studies in Mongolia to further discuss three cross-cutting themes: (1) negotiation of power, resources, and knowledge, as well as balancing contributions from Global North and South; (2) flexibility to adapt to changing contexts in the host setting; and (3) early and proactive building of local government and $\mathrm{NGO} /$ global donor support to implement and sustain programming.

Finally, Ataullahjan, Gaffey, and Bhutta discuss ethical issues when working with conflict-affected populations, especially children and adolescents. Issues of contextual awareness, trust, power, and partnership within research ethics are identified as warranting careful consideration especially in conducting research with this population.

\section{Future Directions and Questions for Further Reflection}

As editors, we strongly feel that there needs to be a more equitable North-South partnership, but even more importantly opportunities for more engaged dialog and greater opportunity for South-South leadership to emerge in global mental health research (Aellah et al. 2016). The experience of emerging economies especially those with good Human Development Index (HDI, an index by UNDP) and Gross Domestic Product (GDP, widely acknowledged index of productivity by World Bank) from the middle-income or middle-to-high-income countries may be critical to support leadership and planning in mental health sector in low-income countries. While knowledge-, resource-, and technology-transfer from North to South has been a prevalent and immensely emancipatory practice, it can become oppressive and dictatorial given that our history is marred by years of European colonization of Africa, Middle East, and Asia and the more recent neoliberal policies of Global North have perpetuated poverty and political instability in the Global South. We need more investment and resources in promotion of an equitable dialogue with those partners who may have dealt with common challenges and developed their health systems expertise pushing boundaries.

Examples of technology- and knowledge-transfer from South to North are also critically needed in providing novel solutions to race, ethnicity, and class divides as well as towards rising religious extremism in the world. Global South is therefore not only an "imaginary" (to use Jacques Lacan's lexicon) to deposit all negative identifications but is also a resource in thinking of partnerships and collaborations to 
optimize development and human well-being globally. If HIV research can pave way for most advanced science, social science, and behavioral interventions worldwide, mental health research in most marginalized countries of the world offers an opportunity for the more developed world to champion and address their health disparities and most marginalized populations.

We know that this theme is much deeper and political and that the discussion around it will evolve further with time. We welcome our readers to critically explore this special issue that focuses on the brass tacks of partnership and ethos of collaborative work in mental health research. We wish that this work would pave way for new ideas, enhanced scholarship, and practice frames on mental health research partnerships.

Funding The study has been funded by NIMH (U19MH110001; 20162021)

\section{Compliance with Ethical Standards}

Conflict of Interest Statement The authors declare that they have no conflict of interest.

Ethical Statement The paper is a desk review and did not involve any data collection from human/animal subjects. As a result we did not receive any IRB approval for this paper.

\section{References}

Aellah, G., Chantler, T., \& Geissler, P. W. (2016). Global health research in an unequal world: ethics case studies from Africa. Oxfordshire: CAB International Available from: https://www.ncbi.nlm.nih.gov/ books/NBK458758/. Accessed 15 Dec 2019.

Bosio, A. C., \& Graffigna, G. (2012). 'Issue-based research' and 'process methodology': reflections on a postgraduate master's programme in qualitative methods. Psychology Learning and Teaching, 11(1), 5259.
Chu, K. M., Jayaraman, S., Kyamanywa, P., \& Ntakiyiruta, G. (2014). Building research capacity in Africa: equity and global health collaborations. PLoS Medicine, 11(3), e1001612. https://doi.org/10. 1371/journal.pmed.1001612.

Gautier, L., Sieleunou, I., \& Kalolo, A. (2018). Deconstructing the notion of "global health research partnerships" across Northern and African contexts. BMC Medical Ethics, 19(Suppl 1), 49. https://doi.org/10. 1186/s12910-018-0280-7.

Kumar, M. (2019). Championing equity, empowerment, and transformational leadership in (mental health) research partnerships: aligning collaborative work with the global development agenda. Frontiers in Psychiatry, 10, 99. https://doi.org/10.3389/fpsyt.2019.00099.

Lairumbi, G. M., Michael, P., Fitzpatrick, R., \& English, M. C. (2011). Ethics in practice: the state of the debate on promoting the social value of global health research in resource poor settings particularly Africa. BMC Medical Ethics, 12(1), 22. https://doi.org/10.1186/ 1472-6939-12-22.

McKay, M., \& Paikoff R. (2007). Community collaborative partnerships: The foundation for HIV prevention research efforts in the United States and internationally. West Hazleton: Haworth Press.

McKay, M., \& Jensen, P. S. (2010). Collaborating with consumers, providers, systems and communities to enhance child mental health services research. In K. Hoagwood, P. S. Jensen, M. McKay, \& S. Olin (Eds.), Redefining the boundaries: Creating partnerships for research to improve children's mental health. Oxford University Press. https://doi.org/10.1093/acprof:oso/9780195307825.003.0001

Myser, C. (2015). Defining global health ethics. Journal of Bioethical Inquiry, 12(1), 5-10. https://doi.org/10.1007/s11673-015-9626-8.

Parker, G., Ali, S., Ringell, K., \& McKay, M. (2014). Bi-directional exchange: the cornerstone of globally focused social work. Global Social Welfare, 1(1), 1-8.

Simon, C., \& Mosavel, M. (2011). Getting personal: ethics, identity in global health research. Developing World Bioethics, 11(2), 82-92. https://doi.org/10.1111/j.1471-8847.2011.00297.x.

Sperber, E., McKay, M. M., Bell, C. C., Petersen, I., Bhana, A., \& Paikoff, R. (2008). Adapting and disseminating a community-collaborative, evidence-based HIV/AIDS prevention programme: lessons from the history of CHAMP. Vulnerable Children and Youth Studies, 3(2), 150-158.

Publisher's Note Springer Nature remains neutral with regard to jurisdictional claims in published maps and institutional affiliations. 